\title{
ЗРИТЕЛЬНЫЙ КОНТАКТ КАК ФОРМА НЕВЕРБАЛЬНОЙ КОММУНИКАЦИИ: ОСНОВНЫЕ ТЕОРЕТИЧЕСКИЕ ПОДХОДЫ
}

\author{
Корнилова В.С. ${ }^{1}$, Сошина Е.A. ${ }^{2}$
}

${ }^{1}$ Московский государственный университет

имени М.В. Ломоносова, г. Москва, Российская Федерация

${ }^{2}$ Школа для глухих детей «Апостол Сантьяго»

Муниципалитета Сантьяго, Чили

Актуальность исследования зрительного контакта как формь невербальной коммуникации неуклонно возрастает в связи с исследовательским интересом поиска и разработки новых ресурсов воздействия на человека в разных сферах жизнедеятельности.

Цель - проведение теоретического анализа литературы по заявленной проблематике для обоснования понятия, особенностей, функции и значения зрительного контакта.

Методика исследования базируется на теоретическом обзоре работ отечественных и зарубежных ученых по проблеме зрительного контакта как формы невербальной коммуникации. В процессе исследования применялись методы теоретического анализа, сравнительного анализа, обобщения.

Результаты. В статье представлен теоретический обзор основных научных подходов к проблеме изучения феномена зрительного контакта в проиессе невербальной коммуникации, набирающего в последнее время популярность в отечественном психологическом сообществе.

Выводы. «Пальма первенства» в исследовании зрительного контакта, как вида невербальной коммуникации, принадлежит зарубежным исследователям, работы которых помогли осмыслить понятия, особенности, функции и значение зрительного контакта.

Ключевые слова: зрительный контакт; визуальный контакт; контакт глаз; невербальная коммуникация. 


\section{EYE CONTACT AS A FORM OF NON-VERBAL COMMUNICATION: THE MAIN THEORETICAL APPROACHES}

\section{Kornilova V.S. ${ }^{1}$, Sochina E.A. ${ }^{2}$}

${ }^{1}$ Lomonosov Moscow State University, Moscow, Russian Federation

${ }^{2}$ Apostol Santiago school for deaf children in the municipality of Santiago, Chile

The relevance of the study of eye contact as a form of nonverbal communication is steadily increasing due to the research interest in the search and development of new resources for influencing people in various spheres of life.

The goal of this research is the theoretical analysis of the learned sources on the stated problematics to substantiate the concept, distinctive features, function and meaning of eye contact.

The research methodology is based on a theoretical review of the works of Russian and foreign scientists on the problem of eye contact as a form of nonverbal communication. Methods of theoretical analysis, comparative analysis and generalization were used during in the course of the research.

Results. The article presents a theoretical overview of the main scientific approaches to the problem of studying the phenomenon of eye contact in the process of non-verbal communication, which has recently gained popularity in the Russian psychological community.

Conclusions. The palm of victory in the study of eye contact as a type of non-verbal communication belongs to the foreign researchers, whose works helped to comprehend the concepts, features, functions and meaning of eye contact.

Keywords: eye contact; visual contact; non-verbal communication.

\section{Актуальность}

Невербальная коммуникация является одной из сфер человеческого общения, при помощи которой происходит более эффективное и быстрое взаимодействие между людьми. Отдельные проявле- 
ния невербальной коммуникации помогают человеку сформировать представление и отношение к собеседнику, определить вид и характер взаимодействия, понять и оценить отношение партнера коммуникации. Интерес и внимание к исследованию невербальной коммуникации и что скрывается за невербальными проявлениями поведения человека, неуклонно растет. Данный факт обусловлен исследовательским интересом поиска и разработки новых ресурсов воздействия на человека в разных сферах жизнедеятельности. Понятие невербальная коммуникация в процессе теоретических и практических исследований дополняется новым смысловым содержанием в контексте выделения функций и значения. Наиболее изученной является кинесическая система, а наименее - область зрительного контакта.

Цель заключается в проведении теоретического анализа литературы по заявленной проблематике для обоснования понятия, особенностей, функции и значения зрительного контакта.

\section{Методика}

Методологической основой исследования является теоретический обзор работ отечественных и зарубежных ученых, в которых рассматривается проблема зрительного контакта как формы невербальной коммуникации. В процессе исследования применялись общенаучные методы: методы теоретического анализа, сравнительного анализа, обобщения.

\section{Результаты}

Отечественные и зарубежные исследователи отмечают важность в установлении зрительного контакта в процессе коммуникации. С помощью зрительного контакта люди передают сообщения, эмоции, отношение друг к другу. Движения глаз, выражая эмоции человека, являются следствием проявления таких качеств, как стеснительность, застенчивость, агрессия, дружелюбие, печаль. Взгляд еще более усиливает эмоциональное состояние человека, отражая нежность, симпатию, уважение, пренебрежение к собеседнику. Не 
случайно, в повседневной речи мы используем такое понятие как глаза - «зеркалом души».

Традиционно при описании зрительного контакта применяют синонимичные понятия «визуальный контакт» и «контакт глаз», так как термин «визуальный» с латинского переводится как visualis зрительный.

Зрительный контакт - это обмен взглядами между партнерами, направление взглядов и продолжительность времени взгляда на партнере. Зрительный контакт, являясь формой невербальной коммуникации, показывает складывающиеся отношения и взаимоотношения между людьми, их включенность в социальное взаимодействие [3]. Обмен взглядами - это ситуация, когда собеседники смотрят друг на друга. Контакт глаз подразумевает взаимные взгляды собеседников не только прямо в глаза, но и на область вокруг глаз.

Ж.П. Сартр отмечал, что постигать взгляд другого - значит иметь сознание того, что является рассматриваемым, в независимости от формы и цвета глаз.

Параметрами зрительного контакта между людьми являются временные и пространственные характеристики, степень интенсивности контакта [4]. Они зависят от традиционных духовно-культурных норм и ценностей, а также индивидуальных особенностей человека. Например, английские традиции предполагают смотреть в глаза людям, проявляя тем самым уважение и интерес к собеседнику. В американской культуре, напротив, избегают контакта глаз, и смотрят только по необходимости, в том случае, если хотят убедиться в том, что их сообщение было воспринято [1]. Россия, являясь страной многонациональной, представляет собой слияние культур и традиций, но, в большинстве своем, придерживается традиции избегать прямого взгляда с незнакомыми людьми, с людьми, которые оказались в неловких или неприличных ситуациях, с опасными людьми и с теми, для кого сам человек представляет опасность и потенциально возможен конфликт [6]. Положительные эмоции сопровождаются частым установлением зрительного контакта, тогда при как при отрицательных люди стремятся избегать его установления. 
C возрастом происходит падение динамики и продолжительности зрительного контакта, характеристики взгляда меняются в отдельных социальных ситуациях и видах речи, в зависимости от содержания и темы высказывания [2].

Средняя продолжительность взгляда составляет 2,95 секунды, а средняя продолжительность обмена взглядами 1,18 секунд [8].

Г.Е. Крейдлин считает направление, объект и тип взгляда, т.е. способ визуального взаимодействия, главным признаком зрительного контакта [2].

На установление и поддержание визуального контакта влияет дистанция, направление взгляда, физические и личностные характеристики человека. Увеличение временных характеристик, таких как продолжительность и интенсивность приводят к увеличению дистанции. Направление взгляда играет важную роль для создания непринужденного общения. Физические характеристики собеседника не так сильно влияют на зрительный контакт, но если человек заранее знает, что будет общаться с неполноценным человек, то он будет смотреть на него реже. На взгляд влияют определенные личностные характеристики, такие как потребность в аффилиации, участие в отношениях или присоединении, мотивация, уровень возбуждения, чувство стыда или низкая самооценка [5].

При учете гендерной специфики зрительного контакта необходимо учитывать два выражения во взглядах: выражение доминирования и власти; выражение привязанности и сердечности. Визуальное доминирование обусловлено различиями в статусе, власти [5]. Женщинам в большей степени важна обратная связь, нежели мужчинам [8], причем им свойственно смотреть на тех, кто им привлекателен. Тогда как у мужчин, напротив, прослеживается обратная зависимость.

О важности зрительного контакта в общении свидетельствует такое его значение, как проявление заинтересованности и внимания собеседников, свидетельство их открытости и искренности [7].

Teresa Farroni, Gergely Csibra, Francesca Simion, Mark H. Johnson, исследуя способность младенцев различать прямой и отведенный взгляд и оценивая нейронную обработку лица при прямом взгляде, 
пришли к выводу, что чувствительность к взаимному взгляду является основной задачей для последующего развития социальных навыков. Младенцы с рождения предпочитают смотреть на лица, которые их привлекают во взаимном взгляде, у них происходит усиление нейронной обработки при прямом взгляде [9].

Исследуя важность в установлении зрительного контакта для поддержания общения, группа американских ученых под руководством Ш. Роджерса провели эксперимент, который заключался в том, что испытуемые сначала смотрели прямо в глаза собеседнику, а потом на его рот. По завершении эксперимента они заполнили опрос, в котором их просили оценить, насколько они были заинтересованы и внимательны в разговоре и насколько он им понравился. Ученые установили, что разницы между тем, куда смотрели испытуемые и был ли установлен зрительный контакт, не имело значения [11]. Зрительный контакт является важным аспектом для установления и поддержания взаимодействия, но не необходимым.

Зрительный контакт, как форма невербальной коммуникации, имеет ряд функций, выделенных английским ученым Адамом Кендоном. Во-первых, регулятивная функция, которая заключается в том, что взгляд регулирует процесс коммуникации, определяя, вызывая или подавляя какую-либо реакцию человека [10]. Зрительный контакт свидетельствует о готовности собеседника воспринимать информацию. Также процесс передачи вербальной и невербальной информации осуществляется при постоянном зрительном контакте.

Во-вторых, эмотивную функцию, заключающуюся в том, что через взгляд человек выражает чувства, эмоции, которые испытывает во время общения, определяя тем самым характер межличностных отношений.

В-третьих, когнитивную функцию. В процессе коммуникации люди передают глазами информацию и пытаются прочесть ее в глазах партнера.

В четвертых, контролирующую функцию, с целью проверки обратной связи, донесения до собеседника информации. Установление 
и поддержание социального взаимодействия происходит с помощью быстрых коротких повторяющихся взглядов. Коммуникатор смотрит на слушающего с целью проверки его заинтересованности, внимательности и увлеченности разговором.

Резюмируя выделенные функции зрительного контакта, А. Кендон обращает внимание на смыслы, выражаемые глазами в процессе коммуникации - от готовности к коммуникации до желания установления контакта и получения информации, выражение чувств [10].

В процессе взаимодействия человек в большей степени стремится установить зрительный контакт во время восприятия информации, а не в процессе ее произнесения, так как отсутствие взгляда позволяет говорящему сконцентрироваться на содержании своих мыслей и высказываний, не сбиваясь. Однако, в конце произнесения фразы говорящий пытается смотреть на собеседника, устанавливая контакт для того, чтобы обозначить, что его мысль завершена.

\section{Выводы}

Первые исследования, посвященные осмыслению понятия, особенностей, функций и значения зрительного контакта, как вида невербальной коммуникации, принадлежат зарубежным исследователям. Отечественные ученые в процессе теоретического и практического анализа корректируют и наращивают составляющие в исследовании феномена зрительного контакта, который является необходимым звеном для более эффективного взаимодействия между людьми. На установление и поддержание зрительного контакта, в первую очередь, влияет дистанция и личностные характеристики человека, косвенно физические и гендерные. Зрительный контакт является формой невербального общения, однако обладает собственными характеристиками и включает в себя такие функции как регулятивную, эмотивную, когнитивную и контролирующую функции, которые объясняют значение зрительного контакта. Зрительный контакт играет важную роль в развитии психологического контакта, формировании доверия и сближения с собеседником. 


\section{Список литературы}

1. Аверкина Л.А. Невербальная коммуникация - важный аспект межкультурной коммуникации // Вестник Московского государственного лингвистического университета. 2008. № 554. С. 123-133.

2. Крейдлин Г.Е. Невербальная семиотика: Язык тела и естественный язык. М.: Новое литературное обозрение, 2002. 592 с.

3. Лабунская В.А. Невербальное поведение (социально-перцептивный подход). Ростов н/Д: Рост. ун-т, 1986. 135 с.

4. Лабунская В.А. Экспрессия человека: общение и межличностное познание. Ростов-на-Дону, 1999. 608 с.

5. Нэпп М., Холл Дж. Невербальное общение: мимика, жесты, движения, позы и их значение: полное рук.: пер. с англ. З. Замчук и др. СПб.: Прайм-Еврознак, 2006. 512 с.

6. Сериков А.Е. Практика избегания взгляда в русской культуре // Вестник самарской гуманитарной академии. 2016. № 1 (19). С. 44-62.

7. Шестопалова Н.Д. Окулесика как смыслообразующий элемент в презентации прямой речи // Вестник Тверского государственного университета. 2015. № 4. С. 189-193.

8. Argyle M. Bodily communication (2nd ed.). L.: Methuen, 1988. 255 p.

1. Farroni T., Csibra G., Simion F., Johnson M.H. Eye contact detection in humans from birth // Cognitive Linguistics. 2013. № 24 (3). C. 457-481.

9. Kendon A. Some functions of gaze direction in social interaction // Acta Psychologica. 1967. № 26 (1). P. 22-63.

10. Rogers S.L., Guidetti O., Speelman C., Longmuir M., \& Phillips R. Contact Is in the Eye of the Beholder: The Eye Contact illusion. Perception. Currently in 'online first' status. 2019. Article published at: https:// journals.sagepub.com/doi/full/10.1177/0301006619827486 (accessed May 5, 2020).

\section{References}

1. Averkina L.A. Neverbalnaya kommunikatsiya -vazhyy aspekt mezhkulturnoy kommunikatsii [Non-verbal communication is an important aspect of intercultural communication]. Vestnik of the Moscow State Linguistic University, 2008, no. 554, pp. 123-133. 
2. Kreydlin G.E. Neverbalnaya semiotika: Yazyk tela I estestvennyy yazyk [Nonverbal Semiotics: Body Language and Natural Language]. Moscow, 2002, 592 p.

3. Labunskaya V.A. Neverbalnoe povedenie (sozialno-perzeptivnyy podkhod) [Non-verbal behavior (social-perceptual approach)]. Rostov-na-Do$\mathrm{nu}, 1986,135 \mathrm{p}$.

4. Labunskaya V.A. Ekspressiya cheloveka: obschenie I mexhlichnostnoe poznanie [Human Expression: Communication and Interpersonal Cognition]. Rostov-na-Donu, 1999, 608 p.

5. Nepp M., Kholl Dzh. Neverbalnoe obschenie: mimika zhesty dvizheniya pozy $i$ ikh znacheniya [Non-verbal communication: facial expressions, gestures, movements, postures and their meaning]. Saint-Petersburg, 2006, $512 \mathrm{p}$.

6. Serikov A.E. Praktika izbeganiya vzglyada v russkoy kulture [Gaze avoidance practices in Russian culture]. Vestnik of Samara Humanitarian Academy, 2016, no. 1 (19), pp. 44-62.

7. Shestopalova N.D. Okulesika kak smysloobrazuyuschiy element v prezentatsii pryamoy rechi [Eve contact as sense construction element of direct speech presentation]. Vestnik of Tver State University, 2015, no.4, pp. 189-193.

8. Argyle M. Bodily communication (2nd ed.). London, 1988, 255 p.

9. Farroni T., Csibra G., Simion F., Johnson M.H. Eye contact detection in humans from birth. Cognitive Linguistics, 2013, no. 24 (3), pp. 457-481.

10. Kendon A. Some functions of gaze direction in social interaction. Acta Psychologica, 1967, no. 26 (1), pp. 22-63.

11. Rogers S.L., Guidetti O., Speelman C., Longmuir M., \& Phillips R. Contact Is in the Eye of the Beholder: The Eye Contact illusion. Perception. Currently in 'online first' status. 2019. Article published at: https://journals.sagepub.com/doi/full/10.1177/0301006619827486 (accessed May $5,2020)$. 